\title{
GESTÃO ESCOLAR DEMOCRÀTICA E A CONSTRUÇÃO DA ESCOLA
}

\author{
DEMOCRATIC SCHOOL MANAGEMENT AND SCHOOL CONSTRUCTION
}

\author{
Elias Oliveira Costa ${ }^{\mathrm{I}}$
}

RESUMO: Este artigo tem por objetivo analisar questões fundamentais e os novos desafios e afetos do gestor escolar, em face das novas demandas que a escola enfrenta, no contexto de uma sociedade que se democratiza e se transforma. Muitos destes desafios. se acham reconhecidos conceitualmente embora, em muitos casos, sejam trabalhados apenas genericamente pela comunidade educacional. Sua notoriedade ocorreu principalmente por terem sido propostos pela Lei de Diretrizes e Bases da Educação Nacional. Tal é o caso da democratização da educação, anteriormente estabelecida pela Constituição de 1988. No entanto, como sua pratica é ainda um livro aberto a experiências consistentes, construção do conhecimento e aprendizagem, e dada a sua centralidade para o desenvolvimento da educação de qualidade, trataremos, especialmente, dessas questões. Emerge, assim, um novo processo educativo, no qual a gestão escolar democrática participativa adquire dimensão articuladora dos recursos humanos, burocráticos e financeiros, objetivando fazer da educação, tanto formal, quanto não formal espaço de formação crítica. A gestão escolar democrática participativa é concebida como elemento de democratização da escola, auxiliando a compreensão da cultura da instituição escolar e seus processos e a articulação das relações sociais, da qual fazem parte, os desafios concretos do contexto histórico.

Palavras Chave: Gestão; Professor. Democrática. Educação.

ABSTRACT: This article aims to analyze fundamental questions and the new challenges and affections of the school manager, in the face of the new demands that the school faces, in the context of a society that is democratized and transformed. Many of these challenges are conceptually recognized, although in many cases they are only addressed generically by the educational community. Their notoriety occurred mainly because they were proposed by the Law of Guidelines and Bases of National Education. Such is the case of the democratization of education, previously established by the 1988 Constitution. However, as its practice is still a book open to consistent experiences, knowledge construction and learning, and given its centrality to the development of quality education, we will address these issues in particular. Thus, a new educational process emerges, in which participative democratic school management acquires a coordinating dimension of human, bureaucratic and financial resources, aiming at making education, both formal and non-formal, a space for critical training. Participatory democratic school management is conceived as an element of school democratization, helping to understand

' Graduado em Educação física e mestre em Ciências da Educação e filiado ao Núcleo de Educação Étnico Racial da Secretaria de Estado da Educação do Amapá. E-mail: sailertelias@gmail.com. 
the culture of the school institution and its processes and the articulation of social relations, of which the concrete challenges of the historical context are part.

Keywords: Management; Teacher. Democratic Education.

\section{INTRODUÇÃO}

O estudo parte do princípio de que a gestão das escolas públicas deve ser compartilhada com os demais sujeitos da comunidade escolar. Pois, de acordo com Vasconcellos (2016) a gestão pensada de forma democrática, pode adquirir uma dimensão muito diferente daquela associada à ideia de comando. Isto significa que se pode administrar por meio do diálogo e do envolvimento do coletivo.

Desta forma, torna-se evidente que a escola e sua equipe estejam preparadas para ocuparem um espaço de compromisso, competência humana, teórica, técnica e política. A consolidação de uma gestão democrática requer inúmeras competências de seus atuantes, onde a participação efetiva deve permear todas as funções da comunidade.

Neste sentido, o presente estudo respalda-se na necessidade de aprofundamento e compreensão acerca das perspectivas e dificuldades que se enfrenta para efetivar uma gestão democrática, onde se destaca a participação dos diversos atores sociais.

A participação e o exercício da cidadania no campo educacional, e mais especificamente na gestão da escola, estão ligados a um processo mais amplo de extensão da cidadania social à cidadania educacional, e, portanto, ligado à sua função social. Diante disso, o autor recomenda que a gestão democrática seja instituída por meio da criação de conselhos deliberativos, eleição para diretores e da necessidade de construção coletiva do projeto político-pedagógico. Dessa forma o estudo levanta a seguinte problemática: De que forma o processo de gestão democrática tem sido construído e conduzido na Escola Estadual Deusolina Sales Farias?

O estudo teve como objetivos analisar como ocorreu o processo de construção da gestão democrática na Escola Estadual Deusolina Sales de Farias procurando elucidar a partir do conhecimento da comunidade escolar o conceito de gestão democrática, caracterizando ainda a forma sistemática do papel do diretor frente as novas exigências educacionais para a concretização de uma gestão efetivamente democrática e autônoma. Nessa construção do processo democrático, buscamos ainda identificar os pontos positivos e negativos que permearam a definição desse processo. 


\section{A GESTÃO DEMOCRÁTICA NAS ESCOLAS PÚBLICAS: MODELOS E CONCEPÇÕES}

A elaboração do processo de gestão democrática nas escolas públicas insere-se no contexto da educação brasileira a partir de 1996, com a Criação da Lei de Diretrizes e Bases da Educação Nacional, Lei no. 9.394/96 que no seu Art. 15, afirma que "Os sistemas de ensino assegurarão às escolas públicas de educação básica que os integram progressivos graus de autonomia pedagógica e administrativa e da gestão financeira observada às normas gerais do direito financeiro público" (BRASIL, 1996, p. 35).

A democracia tem se revelado com significados e conceitos diferenciados em muitos espaços e sob diferentes formas, na educação, por exemplo, modismos que tomam conta da educação pública e afirmam serem democráticos. Monteiro (2007) explica:

A palavra democracia é polissêmica, podendo pois possuir vários significados, dependendo dos interesses particulares de quem a encampa, moldando o discurso democrático a diferentes situações e pode ser utilizada até para designar coisas antagônicas. Os políticos brasileiros, por exemplo, só consideram antidemocráticos os outros. Mas uma coisa é comum: falar em democracia envolve sempre algo de positividade, de liberdade (MONTEIRO, 2007, p. 55).

Nesse contexto, moldam-se os discursos democráticos, dependendo dos interesses particulares. No Brasil, nos países da Europa e em outros países latino-americanos, os partidos de esquerda e os partidos mais progressistas têm assumido a bandeira da democracia como valor universal; no caso do Brasil essa bandeira se fortaleceu devido ao longo período de ditadura militar no país, que perdurou por vinte e um anos (1964-1985).

Entretanto, as críticas a esse modelo são de ordem, principalmente, capitalista, que propagam "a ideologia do Estado neutro, a serviço do bem comum, o que se constitui numa falácia” (MONTEIRO, 2007, p. 56).

De acordo com Coutinho (2002), a democracia deve ser vista em um panorama mais amplo e não somente como um valor universal, representada através das eleições diretas livres, como se automaticamente essas relações se transformassem. Segundo o autor, "o que tem valor universal é esse processo de democratização que se expressa, essencialmente, numa crescente socialização da participação política" (COUTINHO, 2002, p. 17). 
Souza (2009), ao falar sobre o conceito de gestão democrática, faz uma articulação entre a escola pública, a política, o poder e a democracia e identifica alguns elementos que na sua visão: possibilitaram a construção de um conceito de gestão escolar democrática, reconhecendo-a como um processo político que é mais amplo do que apenas as tomadas de decisão e que é sustentado no diálogo e na alteridade, na participação ativa dos sujeitos do universo escolar, na construção coletiva de regras e procedimentos e na constituição de canais de comunicação, de sorte a ampliar o domínio das informações a todas as pessoas que atuam na/sobre a escola (SOUZA, 2009, p.136).

A conquista de uma democracia direta e participativa deve começar na escola, como um aprendizado, sendo, por isso, importante a participação e a abertura de espaços organizados de participação no seu interior, para que os sujeitos escolares que estão envolvidos nos processos possam debater e tomar suas decisões.

\section{I O modelo de gestão democrática}

Em se tratando da educação pública nos últimos anos, considera-se indispensável relembrar as lutas históricas para a institucionalização da gestão democrática como princípio da educação, que foi inscrita na Constituição Federal Brasileira de 1988, após forte pressão dos educadores que participaram da IV Conferência Brasileira de Educação (CBE), em 1986, oportunidade em que escreveram uma Carta conhecida como "Carta de Goiânia”, a qual solicitava que fossem inseridos na Constituição vinte e um princípios básicos que atualmente destacavam a efetiva democratização da sociedade.

Porém, o texto da Constituição Federal Brasileira de 1988 resumiu toda a solicitação dos educadores organizados, na simples expressão "gestão democrática do ensino público na forma da lei".

A Lei de Diretrizes e Bases da Educação Nacional (LDBEN) de 1996, que é a Lei da educação no país, em seu art. I4, também só reafirmou o princípio da gestão democrática, com a seguinte redação: "I - participação dos profissionais da educação na elaboração dos projetos pedagógicos da escola" e II - a "participação das comunidades escolar e local em Conselhos Escolares ou equivalentes”.

No art. I5 destaca-se "os sistemas de ensino assegurarão às unidades escolares públicas de educação básica que os integram progressivos graus de autonomia pedagógica e administrativa e de gestão financeira, observadas as normas gerais de direito financeiro público” (BRASIL, I996, p. 8). 


\subsection{O modelo de gestão patrimonial/autoritária}

Seria desastroso para qualquer instituição priorizar seu patrimônio, tendo em vista apenas aqueles de grande monta, como é o caso de prédio, de mobiliário e de equipamentos, menosprezando uma outra modalidade patrimonial, tão ou, em determinados casos, talvez a mais importantes que aqueles dos quais foram citados garanta a manutenção eficiente do ambiente escolar e, neste intuito, a gestão do patrimônio tornase essencial na busca pela devida realização dos objetivos institucionais.

Neste intuito, Martins, explica que "o planejamento e a organização exigem da equipe gestora de uma escola o domínio da arte de conciliar o tempo e os recursos humanos e materiais no espaço escolar" (2001, p. 63). A partir desta constatação, a escola é vista como um resultado dos que a mantém, e também do ambiente criado em seu redor pela própria comunidade.

A divisão mais didática para todos os materiais que constituem o patrimônio escolar é a seguinte: obras e instalações; equipamentos e material permanente; material de consumo; e material de distribuição gratuita.

Os equipamentos e materiais permanentes constituem aqueles de utilização contínua, por tal motivo merecem uma atenção especial no sentido de conservá-los por um período de tempo mais prolongado.

A este respeito, Martins indica sete características que devem ser apresentadas naquele processo: "qualidade, custo de aquisição, custo de manutenção, versatilidade, facilidade de operação e manuseio, adequação e facilidade de transporte, a segurança e a estética" (2011, p. 66). Todos estes itens demonstram a importância de se seguir sempre um processo adequado para que se obtenham os melhores produtos e, assim, os melhores resultados.

Incluem-se entre tais materiais aparelhos e equipamentos para esportes, aparelhos e utensílios domésticos, coleções e materiais bibliográficos, instrumentos musicais e artísticos, máquinas, etc. 


\section{A PARTICIPAÇÃO, A AUTONOMIA E A DESCENTRALIZAÇÃO COMO MECANISMOS POTENCIALIZADORES DA DEMOCRATIZAÇÃO}

\section{I Autonomia}

A autonomia está presente na gestão da educação, entretanto cada modelo de gestão, tanto o democrático como o gerencial, apresenta a sua bandeira dentro das suas concepções sobre o que seria a autonomia e de como ela se revela no seu modelo de gestão, a partir da concepção teórica empregada.

Nesse sentido, o princípio da autonomia requer vínculos mais estreitos com a comunidade educativa, basicamente os pais, as entidades e as organizações paralelas à escola. A presença da comunidade na escola, especialmente dos pais, tem várias implicações. Prioritariamente os pais e outros representantes participam do Conselho da Escola da Associação de Pais e Mestres para preparar o projeto pedagógico curricular e acompanhar e avaliar a qualidade dos serviços prestados (LIBÂNEO, 20I4, p. I44).

A autonomia escolar na concepção democrática é, para Barroso (2013, p. 26-27), “um campo de forças, onde se confrontam e se equilibram diferentes detentores de influência (interna e externa) dos quais se destacam: o governo, a administração, professores, alunos, pais e outros membros da sociedade local". E essa coletividade se edifica na "confluência de várias lógicas e interesses, sejam políticos, gestionários, profissionais e pedagógicos.

A autonomia escolar tão defendida nos discursos oficiais como diretriz de uma política de governo exige a superação da centralização e a uniformização. É necessário que os sistemas se organizem para que as estruturas formais do sistema permitam um novo tipo de relacionamento, com a participação ativa das escolas dialogando com os sistemas de educação, a partir das suas realidades (MENDONÇA, 2015).

Barroso (2013) afirma que as escolas são espaços privilegiados para o diálogo e a construção da sua identidade e autonomia, pois, através da participação coletiva da comunidade na elaboração do Projeto Político-Pedagógico, é um dos principais mecanismos apontados como momentos de expressão coletiva da comunidade escolar na busca da sua identidade e de sua autonomia. O autor ainda nos revela que a autonomia pressupõe a liberdade (e capacidade) de decidir, ela não se confunde com a "independência”, assim, a autonomia é um conceito relativo. 
Embora não exista uma única forma de inserir um sistema gestão participativa, é possível identificar alguns princípios, valores e prioridades, na organização efetiva dessa gestão. Libâneo (2004, p.79), afirma que: A participação é o principal meio de se assegurar a gestão democrática da escola, possibilitando o envolvimento de profissionais e usuários no processo de tomada de decisões e no funcionamento da organização escolar. Além disso, proporciona um melhor conhecimento dos objetivos e metas, da estrutura organizacional e de sua dinâmica, das relações da escola com a comunidade, e favorece uma aproximação maior entre professores, alunos, pais.

\subsection{Participação}

Para o autor Gadotti, o conceito de participação alicerça-se no de autonomia, que significa a competência das pessoas e dos grupos de dirigirem a sua própria vida. Gadotti (200I, p.47), afirma que a autonomia se refere à criação de novas relações sociais, que se opõem às relações autoritárias existentes. Sendo o oposto da uniformização, ela admite a diferença e supõe a parceria. Por esse motivo, uma escola autônoma não atua de forma isolada, mas em constante intercâmbio com a sociedade.

A participação é um dos principais mecanismos de democratização, não é um conteúdo que se possa transmitir, mas uma mentalidade e um comportamento com ele

coerente. É uma vivência coletiva de modo que somente se pode aprender na práxis grupal, ou seja, só se aprende a participar, participando. A participação é então, entendida como uma necessidade humana e como um elemento central da vida política contemporânea (BORDENAVE, 2013).

O significado de participação possui sentidos diferenciados "incluindo, desde comunicar, anunciar, informar e fazer saber, até tomar-se parte e associar-se (WERLE, 2003, p. 19). Nesse sentido, a participação supõe a relação entre sujeitos autônomos que trocam experiências, vivências, que estabelecem diálogo e que em grupo constroem o conhecimento e se reconstroem.

É um mecanismo importante para a concretização das finalidades da educação e a implantação da gestão democrática que surgiu no campo das relações sociais em meados de I980 como uma forma de mediação para combater as posturas autoritárias e hierárquicas dos diretores de escola advindas da teoria clássica da administração na década de 1970 (PARO, 2015).

\subsection{Descentralização}


O termo "descentralização" tem sido cada vez mais incorporado pelas políticas públicas educacionais, que sem infringir as regras de harmonia do conceito, caracteriza-se como a não centralização da gestão autoritária.

Gadotti e Romão (2017) também afirmam que a participação descentralizada influencia na democratização da gestão e também na melhoria da qualidade de ensino. Todos os segmentos da comunidade podem compreender melhor o funcionamento da escola, conhecer com mais profundidade os que nela estudam e trabalham, intensificar seu envolvimento com ela e, assim, acompanhar melhor a educação ali oferecida.

Compreende-se que a participação no processo da gestão democrática acaba envolvendo professores, alunos, técnicos especialistas em educação e gestores que juntos de modo integrado realização uma transformação da educação emancipadora na sociedade.

\section{EXIGÊNCIAS EDUCACIONAIS PARA UMA GESTÃO DEMOCRÁTICA: AUTONOMA E O PAPEL DO DIRETOR}

Segundo Lucky (2015), é no ano de 1980 que o movimento em favor da Descentralização e da democratização da gestão das escolas públicas é iniciado. A Constituição Federal do Brasil, aprovada no ano de 1988, consolida a gestão democrática nos sistemas públicos de ensino, estabelecendo, nos seus artigos 205 e 206, que a educação brasileira, direito de todos e dever do Estado e da família, seria promovida e incentivada com a colaboração da sociedade, visando o pleno desenvolvimento da pessoa, seu preparo para o exercício da cidadania e sua qualificação para o trabalho.

Em 1996, a Lei de Diretrizes e Bases da Educação (no 9394) regulamentou o contido na Constituição Federal, acima citada, e amplia o rumo da democratização prescrevendo, em seu inciso I art. I3, a participação dos profissionais e da comunidade na elaboração da proposta pedagógica da escola e, no artigo is do mesmo inciso, acena para uma progressiva conquista da autonomia pedagógica e administrativa das unidades escolares. É extraordinário notar que a conceito de gestão educacional ampliou-se associada a outras opiniões globalizantes e enérgicas em educação.

De acordo com a autora Lucky (2000), a escola, ao movimentar-se da administração escolar para a gestão escolar, deixa de garantir a formação competente para que os educandos se tornem cidadãos participativos da sociedade, oferecendo a esses educandos oportunidade para que possam aprender para compreender a vida, a sociedade e a si mesmos, e passa a ser Vista não como uma entidade autoritária e paternalista de 
responsabilidade do Governo, mas como uma organização viva, caracterizada por uma rede de relações de todos que nela atuam ou interferem.

A autora relata quando a escola deixa de desempenhar o seu papel que é de formar pessoas participativas, críticas e formadoras de opiniões perante a sociedade na qual ele vive, a escola deve se reconhecida como uma instituição participativa e autônoma, onde prevalece a coletividade e a participação de toda a comunidade escolar em busca de um só objetivo, uma educação de qualidade.

O diretor da escola, tem papel primordial, é peça fundamental na ação do trabalho coletivo, pois competirá a ele promover o ambiente de fraternidade, de respeito, de diálogo e de responsabilidade entre os alunos e a comunidade escolar, este mesmo ambiente. Constituir uma permanente conversa entre a direção e todos os segmentos da escola é fundamental, pois neles repousa a possibilidade de viabilizar um ensino de qualidade.

O gestor passa ser também um educador, mais sabemos que nem sempre isto acontece, alguns diretores não estão nem agir pra educação, não tem o compromisso, a responsabilidade com o trabalho, muito diretor de escolas não tem formação acadêmica na área da educação e é por esse motivo que a educação pública brasileira estar um caos. Sabemos que cabe a diretor a ação de garantir a efetivação da função educativa que é a motivo primordial da escola.

Segundo Líbaneo (2011) a tarefa dos gestores educacionais visa dirigir e coordenar o andamento dos trabalhos, o clima do trabalho, a eficácia na utilização dos recursos e os meios, em função dos objetivos da escola. $\mathrm{O}$ movimento da gestão em educação reconhece a necessidade de unir algumas mudanças.

\section{I Gestão democrática na escola pontos positivos e negativos}

A democracia enquanto valor universal é prático de colaboração recíproca entre grupos e pessoas é um processo globalizante que, tendencialmente, deve envolver cada indivíduo na plenitude de sua personalidade. (PARO, 20oI, p.25).

Falar em democracia, vem logo a mente, a participação, colaboração, autonomia, será diante do cenário educacional brasileiro nas nossas escolas públicas há tão falada democracia, nas escolas os docentes e todos os sujeitos envolvidos neste processo de ensino. 
$\mathrm{Na}$ tão discutida gestão democrática temos os pontos positivos e os negativos, o ponto positivo: podemos escolher entre aspas os nossos gestores, os professores, educandos e a comunidades escolar tem participação ativa na tomada de decisões relacionadas a escola e seu funcionamento. $O$ ponto negativo: já começa na eleição para gestores, onde nem sempre é o gestor aquele que recebe mais voto, tem a chamada lista dos três mais votados, e é encaminhada para o governador, na verdade continua como sempre, um processo de indicação política.

Pela estrutura da educação no Brasil de hoje, encontram-se, também, várias modalidades de gestão escolar, todas, obviamente, conectadas intimamente a maneira operacional de cada diretor. Em razão disso, é preciso conhecer o que pensa o Diretor da escola-campo da pesquisa sobre suas atribuições e a centralidade do seu trabalho para aprimorar o processo de ensino e aprendizagem na escola.

Por isso, sobre concepção de uma escola democrática enfatiza-se sobre o bom relacionamento com os participantes da gestão escolar e o envolvimento destes nas ações pedagógicas e administrativas. Mas, existem dificuldades e, em razão disso, a gestora, aponta alguns desses contrapontos para a execução de uma gestão realmente democrática.

Entre as dificuldades que existem para se efetivar a gestão democrática destacam-se a indiferença e/ou ausência da comunidade extraescolar para com a necessidade de participação no processo educacional, acompanhando o trabalho desenvolvido e oferecendo apoio aos professores, coordenadores, etc. $\mathrm{Na}$ realidade, um dos entraves para que se efetive a gestão democrática é justamente a pouca participação da comunidade quando convocada a contribuir com a escola, seja através dos encontros e reuniões programadas ou mesmo durante a proposição de projetos específicos que abordem temas de interesse comunitário.

Suas colocações podem ser evidenciadas nas palavras de Libâneo (2014, p.143) ao enfatizar que:

A participação implica os processos de gestão, os modos de fazer, a coordenação e a cobrança dos trabalhos e, decididamente, o cumprimento de responsabilidades compartilhadas conforme uma mínima divisão de tarefas e alto grau de profissionalismo de todos.

Desse modo, é possível perceber que o processo de gestão implica, não somente fazer com que a comunidade participe, mas principalmente gerir esta comunidade onde entram os processos organizacionais em que se faz necessário coordenar toda uma equipe 
de trabalho para que esta realmente venha a assumir suas responsabilidades. Verifica-se que a diretora tem encontrado dificuldades em gerir sua comunidade.

Dentro deste novo modelo de gestão, surge a figura do líder participativo, ou o chamado, diretor-gestor que, obviamente, tem papel fundamental nesta nova estrutura, pelo acentuado grau de responsabilização na consecução dos resultados. A transformação vivenciada no ambiente escolar nasce no papel do líder. Ele motiva, incentiva, direciona, delega, conscientiza, mas, tudo isto no intuito de provocar uma mudança nos paradigmas do passado. (PADILHA, 2002).

Nesse mesmo prisma, assegura Libâneo (2003, p. 330):

Convém ressaltar que o principio participativo não esgota as ações necessárias para assegurar a qualidade de ensino, tanto quanto o processo organizacional, e como um de seus elementos, a participação é apenas um meio de alcançar melhor e mais democraticamente os objetivos da escola, os quais se localizam na qualidade dos processos de ensino e aprendizagem.

O principio da participação implica no que é inevitável: a direção, que dentro da gestão democrática, promove de maneira significante à promoção da gestão coletiva. Isso fica claro quando no decorrer das observações realizadas pelo grupo no período em que esteve envolvido com a pesquisa de campo, principalmente na visita realizada nas dependências da escola e no contato (conversas informais) com os seus membros, verificou-se que a gestora tem dificuldades em fazer com que as responsabilidades sejam assumidas por todos da comunidade, como, por exemplo, quando se trata de participar nas decisões relacionadas as mudanças no calendário ou mesmo nas programações referentes as datas festivas, tomando atitudes e aplicando ordens que deveriam ser discutidas pela Equipe escolar.

Contrapondo tal contexto autores como Bordignon e Gracindo (2016), são específicos quanto à função do administrador escolar ao colocarem que, o gestor é o coordenador, com conhecimento técnico e percepção política, não mais o dono do fazer e, sim, o animador dos processos, o mediador das vontades e seus conflitos. Um gestor capaz de construir e desenvolver a convivência coletiva na escola é aquele que indaga honestamente. O desenvolvimento de habilidades de liderança do gestor é muitas vezes pessoal, porém depende de articulações adequadas entre características pessoais e capacidades de aprender com os outros. 


\section{CONSIDERAÇÕES FINAIS:}

No levantamento bibliográfico deste estudo, puderam-se alcançar os objetivos deste trabalho ao observar algumas questões que denunciaram os entraves para a efetivação da gestão democrática na instituição pesquisada.

Ao analisar a produção bibliográfica percebe-se que o perfil de muitas escolas e do processo de gestão, constataram-se algumas situações apontadas pelos teóricos deste trabalho como fatores para a não funcionalidade da democracia no âmbito escolar como: a falta de formação específica da diretora para o exercício em função; a inexistência de um Projeto Político Pedagógico, um grande instrumento de organização do trabalho escolar, e, apontado como expressão coletiva do esforço da comunidade, na busca por sua identidade, e nesse sentido, como uma das principais expressões de autonomia escolar; além da ausência de um processo eleitoral para a escolha do diretor. Entende-se que, isoladamente, as eleições para diretor não têm força suficiente para assegurar a democratização da gestão, mas, sem elas não se pode falar em um processo verdadeiramente democrático de gestão.

Outro aspecto relevante diz respeito à não participação de pais e alunos nas reuniões administrativas. É de fundamental importância que se estabeleça a articulação entre a escola e a comunidade que a serve, pois a escola não é um órgão isolado e suas ações devem estar voltadas para as necessidades comunitárias com muito trabalho, dedicação, participação para se chegar ao objetivo da educação que é promover o homem dentro de seu contexto social e político.

Realizar uma gestão democrática significa acreditar que todos juntos têm mais chances de encontrar caminhos para atender às expectativas da sociedade a respeito da atuação da escola. Ampliando o número de pessoas que participam do Conselho escolar, é possível estabelecer relações mais flexíveis e menos autoritárias entre educadores e comunidade.

No decorrer deste estudo, pode-se descobrir que alguns caminhos podem ser percorridos para que a escola venha a se tornar uma democracia. Primeiramente, faz-se necessário que toda comunidade escolar, não somente tenha a ciência da importância de uma gestão democrática, mas, principalmente, busque descobrir sobre os caminhos que devem ser percorridos para que ela realmente se efetive.

Portanto, a formação do diretor requer uma especialização na área, para que este possa ampliar as conquistas para níveis mais aprofundados de participação da sociedade, 
tendo como perspectiva a superação de modelos verticalizados por relações mais horizontais, onde a democracia seja, cada vez mais, compreendida como valor político e social.

Embora a gestão democrática esteja, atualmente, bastante presente nos discursos, ela exige de todos os profissionais uma afirmação concreta, exercitada cotidianamente nas relações dentro e fora da escola. A cultura democrática está longe de ser uma realidade consolidada, e necessita do trabalho diligente de todos que se preocupam com uma gestão qualitativa, em especial no espaço educacional, ponto de encontro de gerações tanto na conservação da história e produção de conhecimentos, quanto na inovação e transformação cultural.

Apesar de compreender que a efetivação da gestão democrática na escola é um processo que requer a cada instituição uma longa caminhada de estudos e experiências, entende-se que o curso sobre esta temática não se conclui nos parâmetros optados por este trabalho, pela sua complexidade e necessidade de que novos horizontes sejam traçados, pretende-se ainda, em novos estudos, ampliar os conhecimentos sobre este processo de transformação, que resgata inicialmente as referências coletivas do ser humano e a convicção de que ele pode intervir no processo de construção histórica da sociedade através da democracia no campo educacional.

\section{REFERÊNCIAS}

AZEVEDO, Janete M. Lins de. A Educação como Política Pública. 2.ed. Campinas: Autores Associados, 2006. (Coleção Polêmicas do nosso tempo: vol. 56).

BORDIGNON, Genuíno; GRACINDO, Regina Vinhaes. Gestão da Educação: o município e a escola. In: CATÂNI, Afrânio Mendes (Org.). Gestão da Educação. Impasses, perspectivas e compromissos. 5.ed. São Paulo: Cortez, 2006.

BRASIL. Constituição 1988. Texto Constitucional de 5/10/88 com as alterações adotadas pelas Emendas Constitucionais até 1998. Brasília: Câmara dos Deputados, Coordenação de Publicações, 1998.

BRASIL, Ministério da Educação. Lei 4.024, de 20 de dezembro de 1961, que "fixa diretrizes e bases da educação nacional”. Brasília, Diário Oficial da União, v.ı,p.12-429.

. Lei 5692, de II de agosto de 1971, que "fixa diretrizes e bases para o ensino de Io e $2^{\text {o }}$ graus e dá outras providências”. Diário Oficial da União. Brasília, v.I, p.6.377, de 12/o8/7I.

Lei de Diretrizes e Bases da Educação Nacional. no 9.394/96. Brasília: MEC, 1996. 
BRASIL, Ministério da Justiça. UNESCO. Gestão da escola fundamental. Brasília: Cortez, 1993.

. Estatuto da Criança e do Adolescente. Lei no 8o69, de julho de 1990.

BRABO, Tânia S. A. M. Democratização da escola sob uma perspectiva de gênero. In: Revista ORG\&DEMO, Marília, v.5, n.I, P.55-78, 2004.

DEMO, Pedro. Professor do futuro e reconstrução do conhecimento. Petrópolis, RJ: Vozes, 2004.

DIAS, José Augusto. A gestão democrática na escola. In: MENEZES, João Gualberto de Carvalho. (Org.). Educação básica: Políticas, legislação e gestão - leituras. São Paulo: Pioneira Thompson Learning, 2004.

GHIRALDELLI JÚNIOR, Paulo. História da educação. São Paulo: Cortez, I99ı.

CONSELHO FEDERAL DE EDUCAÇÃO. Parecer 252, de in de abril de 1969. Define o currículo mínimo e a duração para o curso de graduação em pedagogia. Disponível em: http: // www.inep.gov.br. Acesso em: 10/07/2007.

DOURADO, Luiz Fernandes. A gestão democrática e a construção de processos Coletivos de participação e decisão na escola. Campinas: São Paulo, Papirus, 2002.

FERREIRA, Naura S. Carapeto (Org.). Gestão democrática da educação: atuais tendências, novos desafios. 3.ed. São Paulo: Cortez, 2000.

GADOTTI, Moacir. Escola cidadã. 4. ed., São Paulo, Cortez, 2004.

\& ROMÃO, José (Org.) Autonomia da escola: princípios e propostas. São Paulo: Cortez, 1997.

LIBÂNEO, José Carlos. Organização e gestão da escola: teoria e prática. 5. ed. Goiânia: Alternativa, 2004.

. Educação escolar: políticas, estrutura e organização. São Paulo: Cortez, 2003.

LIMA, Licínio C. Organização escolar e democracia radical: Paulo Freire e a governação democrática da escola pública. São Paulo: Cortez, 2002.

.et al. A escola participativa: o trabalho do gestor escolar. 6. ed. Rio de Janeiro: DP\&A, 2003.

.Perspectivas da Gestão Escolar e Implicações quanto à Formação dos seus Gestores. Revista emAberto, Brasília, v.17, n 72, fevereiro/junho 2000.

MARTINS, Ângela Maria. Autonomia da escola: a extensão do tema nas políticas públicas. São Paulo: Cortez, 2002. 
MEKSENAS, Paulo. Cidadania, poder e comunicação. São Paulo: Cortez, 2002.

MELCHIOR, José Carlos de Araújo. Mudanças no financiamento da educação no Brasil. Campinas: Autores Associados, 1997.

MICHEL, Maria Helena. Metodologia e pesquisa científica em Ciências Sociais: Um guia prático para acompanhamento da disciplina e elaboração de trabalhos monográficos. São Paulo: Atlas, 2005.

NOGUEIRA, Martha Guanaes. Supervisão educacional: a questão política. São Paulo: Loyola, 1989.

NÓVOA, Antonio. (coord.) Os professores e a sua formação. $2^{\mathrm{a}}$ ed. Lisboa Dom Quixote, I99I.

OLIVEIRA, Dalila Andrade. A gestão democrática da educação no contexto da reforma do Estado. In: CATÂNI, Afrânio Mendes (Org.). Gestão da educação. Impasses, perspectivas e compromissos. 5.ed. São Paulo: Cortez, 2006. p.91-II2.

Mudanças na Organização e gestão do trabalho na escola. Belo Horizonte: Autentica, 2002.

PADILHA, Paulo Roberto. Planejamento dialógico: como construir o projeto políticopedagógico da escola. 4. ed. São Paulo: Cortez, 2003.

PAIVA, Edil V. de (Org.) Pesquisando a formação de professores. Rio de Janeiro: DP\&A, 2003.

PARO, Vitor Henrique. Escritos sobre educação. São Paulo: Xamã, 20oI.

Administração escolar: introdução crítica. II.ed. São Paulo: Cortez, 1993.

Gestão democrática da escola pública. São Paulo: Ática, 2002.

SANTOS, Boaventura de Souza. Democratizar a democracia: os caminhos da democracia participativa Rio de Janeiro: Civilização Brasileira, 2002.

SAVIANI, Dermeval. A Supervisão educacional em perspectiva histórica: da função à profissão pela mediação da idéia. In: FERREIRA, Naura S. C. (Org.). Supervisão educacional para uma escola de qualidade. São Paulo: Cortez, I999.

SILVA, José Maria da; SILVEIRA, Emerson Sena da. Apresentação de trabalhos acadêmicos: normas e técnica. Petrópolis, RJ: Vozes, 2007.

SILVA JÚNIOR, C. A. Organização do trabalho na escola: a prática existente e a teoria necessária. Cadernos de Pesquisa, São Paulo: v. 59, p. 73 - 76, nov. 1986. 
VIANNA, Ilca Oliveira de Almeida. Planejamento participativo na escola. São Paulo: EPU, 2000.

VIEIRA, Sofia Lerch (Org.). Gestão da escola: Desafios a enfrentar. Rio de Janeiro: DP\&A, 2002.

os alunos aprendem de menos e cada vez menos! Aprendem menos porque os assuntos são a cada dia mais desinteressantes. Petrópolis, RJ. Vozes, 2002. 